\title{
Mechanical properties of Methacrylic Plexus MA300 adhesive material determined in tensile test and butt joints of aluminum thick plates
}

\author{
Paweł Maćkowiak ${ }^{1 *}$, Dominika Płaczek ${ }^{1}$, and Agnieszka Sołtysiak ${ }^{1}$ \\ ${ }^{1}$ Faculty of Mechanical Engineering, University of Science and Technology, Al. prof. S. Kaliskiego 7, \\ 85-796 Bydgoszcz, Poland
}

\begin{abstract}
Adhesive joints are an alternative method of joining elements. New adhesives achieve cohesion and adhesion strength comparable with plastics used for structural components and coatings. Bonding is faster, simpler and cheaper. For this reason, adhesive joints are increasingly replacing other types of connections. Tests show that the material properties in the cast adhesive specimens differ from the ones determined in the joint. Adhesive producers most often describe the strength of the overlap joint tested in accordance with ASTM D1002. Strength, modulus of elasticity and elongation to break tested in accordance with ASTM D638 are reported less frequently. The article presents a method for determining the mechanical properties of the adhesive in a butt joint and differences in the determined values in relation to the cast specimens on the example of methacrylic adhesive Plexus MA300. The tests were carried out for joining aluminium rod with a square cross-section of $15 \mathrm{~mm}$ x $15 \mathrm{~mm}$ and adhesive layer thickness of approximately $1 \mathrm{~mm}$. The fractures of cast specimens and butt joints were analyzed.
\end{abstract}

\section{Introduction}

Adhesive joints are an alternative method of joining elements. New adhesives achieve cohesion and adhesion strength comparable with plastics used for structural components and coatings [1-2]. Bonding is faster, simpler and cheaper. For these reasons, adhesive joints are increasingly replacing other joining techniques [3-8].

Structural joints must have a certain fatigue durability and strength. In computational methods, it is assumed that the stresses occurring in the material must be less than or equal to the allowable stresses. Calculating and designing adhesives joints requires knowledge of the material data of adhesives and bonded materials $[9,10]$. Determination of mechanical properties of adhesives is associated with technological problems. The first is to obtain specimens from high adhesion material. Therefore, the molds are made of materials difficult to glue such as: politetrafluoroetylen (PTFE), polyethylene, silicone $[4,7,11]$. Adhesive materials differ in viscosity and shrinkage in the cross-linking process, which means that it is not possible to use one method for obtaining repeatable specimens. The

* Corresponding author: pawel.mackowiak@utp.edu.pl 
second problem is to obtain a specimens with properties similar to those of the adhesive layer in joints. The difference may consist in applying the appropriate pressure and heat dissipation that is generated during the crosslinking process. The volume of adhesive in the joint is small, which causes a small amount of heat generated, which can additionally be returned to the connected elements [5]. All this means that the mechanical properties determined on the basis of cast samples may differ from those that occur in the adhesive joint.

The article presents a method for determining the mechanical properties of the adhesive in a butt joint and differences in the determined values in relation to the cast specimens on the example of methacrylic adhesive Plexus MA300. The tests were carried out for joining aluminium rod with a square cross-section of $15 \mathrm{~mm}$ x $15 \mathrm{~mm}$ and adhesive layer thickness of approximately $1 \mathrm{~mm}$. The fractures of cast specimens and butt joints were analyzed.

\section{Methods}

\subsection{Material and method of specimens preparation}

The material for testing was two-component structural methacrylic adhesive: Plexus MA300 adhesive. This glue is used for joining metals, plastics and ceramics. The specimens for determining mechanical properties in a tension test were designed in accordance with the PN-EN ISO 527-2-1998 standard. Dimensions for a small 1BB shape specimen were used [4,5]. The dimensions are shown in the figure 1a. Specimen for testing the strength of butt joints were made in accordance with PN EN 15870 standard. The dimensions of the specimens are shown in the figure $1 \mathrm{~b}$.

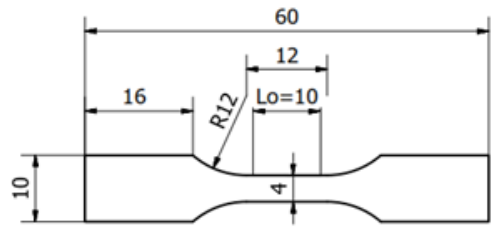

a)

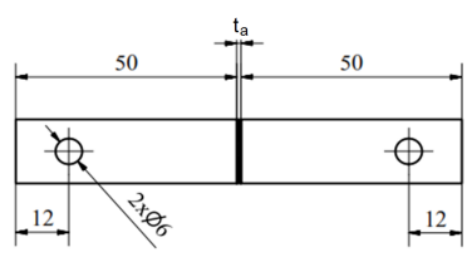

b)

Fig. 1. a) Dimensions of the test specimens of Methacrylic Plexus MA300 for mechanical properties under static tension based on PN-EN ISO 527-2-1998; b) Dimensions of the test specimens for testing the strength of butt joints of aluminium and Methacrylic Plexus MA300 based on PN-EN ISO 527-21998 PN EN

Specimens of methacrylic adhesive (Figure 2a) with $3 \mathrm{~mm}$ of thickness were made from cast plates with dimensions of $75 \mathrm{~mm} \times 45 \mathrm{~mm} \times 5 \mathrm{~mm}$. After curing, plates of methacrylic were removed from the molds. Then, the final shape of the specimens was milled [4]. Specimens of butt joints were made of glued aluminum rods with a square cross-section of $15 \mathrm{~mm} \times 15 \mathrm{~mm}$ and adhesive layer thickness of approximately $1 \mathrm{~mm}$. Adequate thickness of the adhesive and axial alignment of the parts during gluing were obtained by using the fixing device.

The specimens of the cast material and the butt joint specimens were seasoned for one month in room conditions $\left(20 \pm 2^{\circ} \mathrm{C}\right.$, humidity $\left.45 \pm 5 \%\right)$ and then tested. 


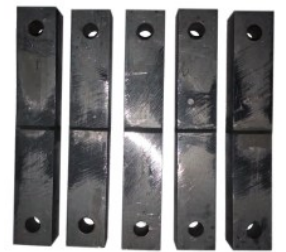

a)

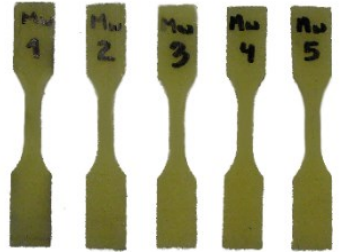

b)

Fig. 2. Specimens of methacrylic adhesive Plexus MA300 a) for tensile test; b) aluminium thick plate butt joints for tensile tests

\subsection{Test method}

During the tensile test, specimens were fixed in the mechanical jaw holders of the INSTRON 5966 strength testing machine shown in Figure 3a. Force sensor with a range of up to $10 \mathrm{kN}$ was used. The test was controlled by a displacement at a constant speed of $0.005 \mathrm{~mm} / \mathrm{s}$. An extensometer was used to measure longitudinal strain. Device used has 10 $\mathrm{mm}$ measurement base and a measuring range of $\pm 1 \mathrm{~mm}$. It is shown in the Figure $3 \mathrm{~b}$.

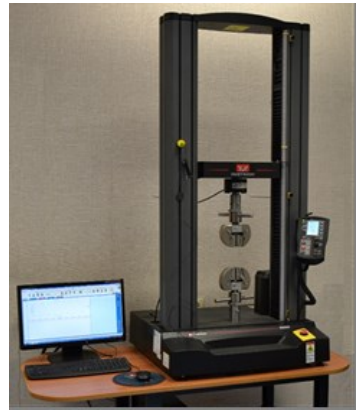

a)

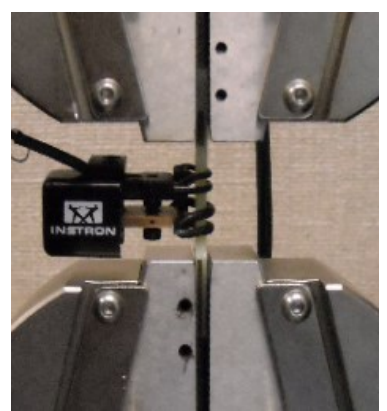

b)

Fig. 3. a) Strength testing machine INSTRON 5966; b) tensile test and specimens in holders

Specimens of butt joints were tested on the same strength machine. Specimens were mounted in holders having a joint, which is shown in Figure 4. The presence of joints allowed to reduce the impact of errors of non-axial bonding of sample elements and nonaxial alignment of holders of a testing machine. Due to much higher stiffness of joined materials in relation to adhesives, it is in the joint that the greatest deformation occurs and pre-stresses occur. The tests were carried out on 5 specimens of each material in ambient conditions.

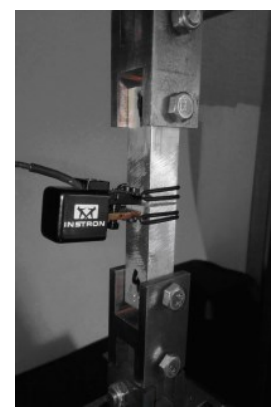

Fig. 4. Butt joint specimen in holders 


\subsection{Calculation of deformations in the adhesive layer in butt tests}

In the butt joints specimens, the deformation measurement included fragments of joined aluminum elements and a layer of adhesive. The thickness of the adhesive layer was measured by means of a measuring microscope. On the basis of the length of the measuring base $1_{b}$ and the thickness of the adhesives layer $t_{a}$, the length of aluminum elements $1_{e}$ included in the legs of the extensometer can be determined:

$$
l_{e}=l_{b}-t_{a}
$$

On the basis of the measured tensile force $\mathrm{F}$ and the known elastic modulus aluminum $E_{e}$ and the surface area of the stretched rods $A_{e}$, the elongation value of the aluminum fragments $\Delta \mathrm{l}_{\mathrm{e}}$ part of the sample covered by the legs of the extensometer can be determined:

$$
\Delta l_{e}=\frac{F \cdot l_{e}}{A_{e} \cdot E_{e}}
$$

Subtracting from the value of the measured relative deformation $\Delta \mathrm{l}_{\mathrm{b}}$, the value of the absolute aluminum deformation $\Delta \mathrm{l}_{\mathrm{e}}$ determined from the previous formula gives the deformation value in the adhesive layer $\Delta \mathrm{t}_{\mathrm{a}}$ :

$$
\Delta t_{a}=\Delta l_{b}-\Delta l_{e}
$$

On this basis, you can already determine the value of the absolute engineering strain in the adhesive layer using the formula:

$$
\varepsilon_{a}=\frac{\Delta t_{a}}{t_{a}}
$$

\section{Test results}

The graphs (Figure 5) present examples of engineering stress as a function of longitudinal engineering strain for the tested material. For the methacrylic the yield point can be determined in the form of stress values at which the deformation occurs without further load increase. The methacrylic adhesive has high strength compared to other structural adhesives. Specimens reached a high elongation before rupture, which was $19.4 \%$ on average. A plastic breakthrough was obtained, characterized by narrowing of the crosssection and change of the color from translucent yellow to white opaque.

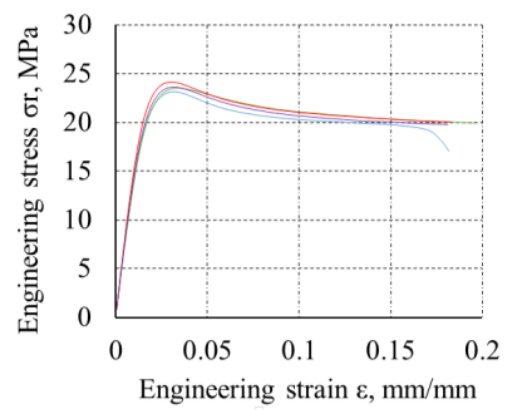

Fig. 5. Engineering stress diagram as a function of engineering strain for Plexus MA300 methacrylic adhesive. 
The exemplary results of the butt joints tests are shown in the graph (Fig.6a). On the basis of the transformations from subsection 2.3, it is possible to develop engineering stress diagrams as a function of engineering strain: the entire measuring section, aluminum fragments covered by the legs of the extensometer and the adhesive layer itself. The graph is shown in Figure $6 b$.

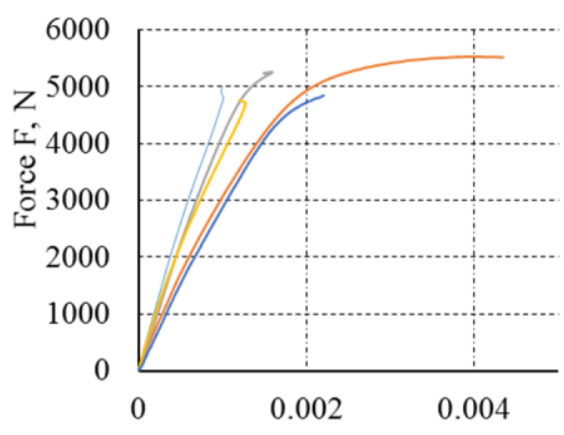

Engineering strain $\varepsilon, \mathrm{MPa}$

a)

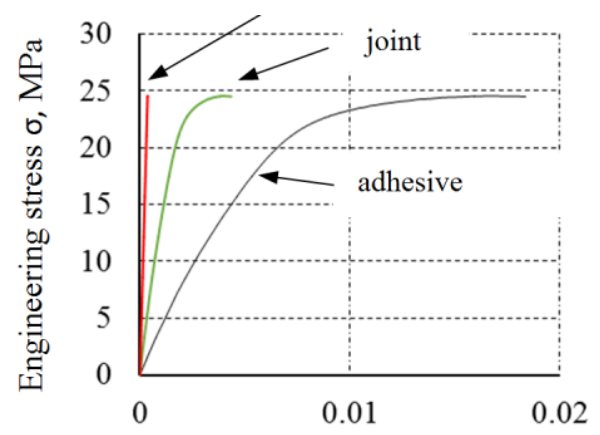

Engineering strain $\varepsilon, \mathrm{MPa}$

b)

Fig. 6. a) Force diagram as a function of strain for butt joint specimens; b) engineering stress diagram as a function of engineering strain for joint, aluminum and adhesive.

Table 1 presents the average results of tests of mechanical properties of structural methacrylic adhesive Plexus MA300 determined in the tensile tests and determined in the butt joint tests. The data provided by the producers are given in brackets. The maximum nominal stresses in the adhesive in the joint have reached a lower value than in the cast specimens. The calculated Young's modulus for adhesive in the joint was more than 2.5 times higher. The butt joint specimens broke brittle. The obtained breakthrough was mixed, in a large part $50-80 \%$ cohesive. The adhesive changed its color, as a result of stretching, only in small areas of cohesive failure. Due to the small elongation before destruction $(0.96 \%)$, probably the plastic state in the material did not develop in the whole crosssection. Testing the adhesive properties in a butt joint is characterized by a definitely greater value of the measurement spread.

Table 1. Determined mechanical properties of the tested adhesives

\begin{tabular}{|c|c|c|c|c|c|}
\hline \multirow{2}{*}{ Mechanical properties } & \multicolumn{2}{|c|}{ Tensile test } & \multicolumn{2}{c|}{ Butt joint test } \\
\cline { 3 - 6 } & Average & $\begin{array}{c}\text { Standard } \\
\text { deviation }\end{array}$ & Average & $\begin{array}{c}\text { Standard } \\
\text { deviation }\end{array}$ \\
\hline Tensile strength & $\mathrm{MPa}$ & $\begin{array}{c}23.7 \\
(22)\end{array}$ & 0.4 & 22.5 & 1.5 \\
\hline Yield strength & $\mathrm{MPa}$ & 23.7 & 0.4 & 21.2 & 0.7 \\
\hline Young's modulus Ea & $\mathrm{MPa}$ & $\begin{array}{c}1610.5 \\
(1034)\end{array}$ & 52.9 & 4354.4 & 244.8 \\
\hline Elongation, A & $\%$ & 19.4 & 0.9 & 0.96 & 0.52 \\
\hline
\end{tabular}

\section{Conclusions}

Determining the mechanical properties of adhesive materials is a complex process. The final results are influenced by many factors: dimensions, method, conditions of specimens manufacturing, measurement method and defects occurring in the adhesive layer. The two methods of measuring the mechanical properties of the adhesive presented in the article give different results. The greatest convergence is obtained for tensile strength, the smallest 
for Young's modulus $E_{\mathrm{a}}$. In the casted samples, a smaller spread of results can be observed, than the results obtained from testing of butt joints. The cause may be measurement errors of the thickness of the adhesive layer, errors resulting from the measurement of smaller strains in the joint and errors resulting from the applied method of calculating the deformations in the adhesive. In addition, due to the larger cross-sectional area of the adhesive joint, it is more difficult to obtain a total lack of defects. Another phenomenon is blocking the possibility of transverse deformation of adhesive at the interface between adhesive and adherends.

\section{References}

1. R. D. Adam, W. C. Wake and M. J. Kamper, Structural Adhesive Joints in Engineering, Elsevier (1984)

2. D. Boroński, M. Kotyk, P. Maćkowiak, L. Śnieżek, Mater Design, 133 (2017)

3. P. Maćkowiak, B. Ligaj, Enginering Mechanics, 1 (2017)

4. P. Maćkowiak, B. Ligaj, D. Płaczek, A. Jasińska, Autobusy 12 (2017)

5. P. Maćkowiak, D. Płaczek, M. Kotyk, Determination of design mechanical properties of adhesives in a tensile and compression test, IOP Conference Series: Materials Science and Engineering 393 (2018)

6. L. F. M. Da Silva, R. D. Adams, J Adhes Sci Technol, 19(3) (2005)

7. L. F. M. Da Silva, B. Blackman, R. D. Adams, Testing Adhesive Joints, John Wiley \& Sons (2012)

8. R. Sołtysiak, T. Giętka, A. Sołtysiak, Advances in Mechanical Engineering, 734 (2018)

9. R. Sołtysiak, J. Małecka, Mater Sci Eng A Struct Mater., 10 (1) (2018)

10. L.R. Xu, S. Sengupta, H. Kuai, Int J Adhes Adhes., 24 (6) (2004)

11. K. Zhao, L.R. Xu, J Adhesion, 91(12) (2015) 